\title{
A Practical Study of Production-orientated Approach: Setting Output Targets in Layers and Diversified Evaluation
}

\author{
Aihua Zhu \\ Guangzhou College of Technology and Business \\ Guangzhou, China
}

\begin{abstract}
The theory of production-oriented approach is a foreign language teaching method with Chinese characteristics. It advocates combining learning with output, driving output with input, enabling students to carry out selective learning and promote study with assessment. However, POA is only applicable to middle-level and high-level English-speaking students and lacks related teaching materials. Generally, undergraduate colleges need to set multilevel teaching goals accordingly. Students can be encouraged to actively participate in the building of learning materials, multiple evaluations should be implemented to achieve the goal of promoting study through assessment. This paper used one class as an example of POA theory practice, setting output targets in layers, adapting in-group out-group evaluation and teacher evaluation. And finally, it has explored the role of diversified assessment in promoting learning.
\end{abstract}

Keywords-production-oriented approach; multilevel teaching goals; diversified evaluations

\section{INTRODUCTION}

The production-oriented approach is a foreign language teaching method with Chinese characteristics, hereafter referred to as POA, its development has experienced for decades. In 2015, the POA system was formed and named formally. This is the wisdom of Chinese scholars as well as researchers aboard. Its teaching philosophy is a combination of principles of learning-centered, learning-using integration , and whole person education it includes output-driven hypothesis, input-enabled hypothesis, selective-learning hypothesis, and evaluation-based learning; The teaching process of POA is composed of out-put driven, enabling, and assessing (Qiufang Wen 2015). These three phases of teaching must give full play to the leading role of teachers, while advocate the combination of "learning and using", and "combine input enabling with "productive utilization"

Many teachers have practiced this teaching method and achieved a lot. (Wenjuan Zhang 2016, 2017; Lingli Zhang 2017 , etc.) From these teaching cases, it is not difficult to see that the output-oriented teaching method has higher requirements for students and teachers.

- It is only feasible for students of middle-high English level. For second or third grade college in which students' English levels are severely differentiated, it is difficult to use POA teaching methods. We need to adjust and localize this approach so as to enable students to complete effective learning.

- For teachers, first of all, the current college English textbooks are not specialized POA materials, and there are no supporting audio and video resources. The topics and contents selected in textbooks are not necessarily suitable for POA teaching methods. Teachers should specifically adapt textbooks .Furthermore they have to excerpt and search for additional materials to enrich classroom teaching, which makes it a bottlenecks for POA application.

The workload of college English teachers in China is relatively large. The process of designing one class of POA is equivalent to the re-editing process of a section of teaching materials. This is the conclusion obtained by many teachers who are using the existing teaching materials to practice the POA teaching method. To improve this situation, teachers can guide students to select topics and find extracurricular materials. Students decide what they want to learn in the classroom, choose what they are interested in and handle it to teachers for review beforehand, while in class teacher can display it as a contributing material in the classroom.

In this article POA theory is practiced in the course of College English Listening and Speaking. By explaining this theory from the perspective of goal setting, teaching material co-construction, task implementing, and evaluation diversifying, the author tries to enrich the POA theory in the application of this course.

\section{THE PRACTISE OF POA THEORY IN CLASS}

The students selected for this study are from electronics department, whose English proficiency level is severely differentiated. There are difficulties in different aspects of learning, such as content, vocabulary, sentence structure, and discourse organization. Traditional classroom teaching activity can not satisfy every student's needs. Teachers cannot be targeted to help every student in every aspect therefore the purpose of effective teaching cannot be achieved. In order to solve the problems, POA teaching 
method was employed. The following took a class as an example to discuss the effect of the POA teaching theory.

\section{A. Teaching Contents}

The textbook used was new progressive English instead of special POA textbook. Homes was selected as theme in this practice, abandoned some of the basic vocabulary and sentence patterns, such as there be sentence type, broadened the cultural content. Students observed the characteristics of houses in different cultures and compared the differences between Chinese and Western houses. To choose this topic, not only students' comprehensive language skills were considered, but also with the objective of achieving intercultural competence.

\section{B. Teaching Goal}

1) The overall goal of this course: to improve students' ability to practice listening and speaking — to use English knowledge they have learned to do things. Students integrate the audio and video materials they have heard and watched to improve the efficiency of selecting input, and learn the contents they need to produce. Due to differences in students' English proficiency, the language task setting varies from person to person, from lower to advanced level.

- Task1: to be able to talk about their favorite housing type and briefly explain the reason;

- Task 2: to be able to describe their favorite housing;

- Task 3: to be able to comment on the characteristics of Chinese and western house and design their favorite house.

2) Language goals are as follows: Communication goals: complete sentences expressing personal preferences, choices; Can describe the relevant words and phrases of the house: apartment, cabinet, neighborhood, castle, container, villa, cottage, core family, magnificent, natural and permanent ,style, material ,reflection etc. sentence pattern :likelpreferlwould rather..etc. descriptive sentences: the main difference between.... Sth. is made of...it reflects...etc.

Cultural goals: to know about the different styles of houses; to understand the different national psychology and values of different housing construction; to have basic cultural identification capabilities and advocate green living environments; to establish the cultural self-esteem of their own nation. Regardless of the level of English, this goal can basically be achieved.

\section{Teaching Process: Including Three Parts: Output Task Driven, Enabling and Assessing}

1) Output task driven: PPT slides were used to display the weird houses around the world as a guide, inspiring students' enthusiasm and interest in learning. Many of the world's most uniquely shaped house buildings represent human imagination and creativity. For example: tilted house, cube house, shoe house etc., students were guided to imagine and describe the house they wanted to live in and try simple drawing and oral expression first, then discuss in the group, and finally describe on stage. This is a preparation of "creating hunger for students" (Qiufang Wen 2014), inspiring students' enthusiasm.

2) Enabling: In this part, teacher plays an intermediary role in guiding students to select appropriate input materials to complete tasks. Language-enabling materials come from textbooks and extracurricular. four sections of Audiovisual materials were selected, and a section of graphic supplement materials downloaded from the internet was added.

a) Input materials should be handled flexibly based on learning objectives from easy to difficult: According to the requirements of teaching objectives, the listening materials were adjusted from easy to difficult, The four audiovisual contents that students need to complete were as follows:

- Listen to recordings to judge personal opinions, preferences and explain why. Students learn how to express their preferences from this task and understand the characteristics of different types of housing, therefore laying the foundation for the completion of major tasks.

- Listen and complete the blanks .The purpose of this task is to complete the description of the internal environment of the house, pay attention to the use of prepositions, and descriptive sentence.

- Listen to the recording to fill in the numbers. Audio recording shows foreign mini-houses and container houses. The specific content includes the size of the house, the number of rooms, the price, and how many people can live. Students learn to describe the house from the appearance to value and try to express concrete expressions such as square meters, flat feet, etc. Tasks above are easy to accomplish and are intended to lay the groundwork for accomplishing language tasks1 (expressing personal preferences) and task2 (describing your favorite housing).

- Video materials show new eco-friendly home. Students learn how to be energy-efficient and environmental friendly. The completion of this task is an extension of the previous three tasks and can also be seen as a deepening of the major tasks.

b) Students summarize what they have learned from the 4 audiovisual materials: This stage is very important. POA emphasizes the theory of learning centered and integrates learning and using. After completing task 4, teachers play a guiding role and ask students to sum up expressions learned in this lesson. Their role in this stage is a listener. if the key element is missing, supplements should be made.

c) Extending extra-curricular materials, students independently perform output task: The extracurricular input-enabling material can be collected by students in 
advance. Teachers can ask students' opinions beforehand what do they want to know about this topic and assign tasks of collecting more learning materials, including graphic, videos and Submitting PPT. Teachers make appropriate modifications if necessary. About this topic, students chose to introduce Chinese traditional houses such as courtyard, stilted house, caves earth building and western buildings such castle, church and Parthenon. Students were encouraged to describe them and try to design their favorite house. Finally they perform their task in the front.

In this session, students not only described their favorite houses, but also extended to the characteristics of Chinese and Western architecture and profoundly commented the differences between Chinese and Western architectural cultures.

3) Assessing: Compared with traditional pedagogy, POA theory requires students to complete more output tasks in various types. In contrast with English majors, levels of non-English majors are uneven. With more than 60 students in one class, teaching evaluation is difficult to be made. However, if there is no impartial evaluation and feedback, the enthusiasm of the students will be frustrated. To solve this problem, many Chinese scholars have conducted empirical research on evaluation. It is proved that these methods have certain results, but each has its own advantages and disadvantages.Qiufang Wen(2016) proposed an innovative evaluation model of POA theory named Teacher-Student collaboration Mechanism, Hereinafter referred to as TSCA, which divides assessment into three stages: preparation before class, implementation in class, and after-class activities. It points out that the implementation of TSCA is the most important in class and after class activities, an integral part of TSCA. In this teaching process, a multi-assessing approach was adopted, which combines student self-assessment, in group assessment, outside group assessment, and teacher's evaluation with regard to learning attitude, participation, and learning effectiveness. Before the implementation of POA teaching, students were grouped in pairs. In practice; it was not difficult to find that students are still convinced that teachers' evaluations are more authoritative and more reliable.

a) In-group Evaluation: In-group evaluation criteria were fixed as follows:

TABLE I. IN-GROUP EVALUATION SCORE

\begin{tabular}{|c|c|c|c|}
\hline Name & $\begin{array}{c}\text { participation } \\
(\mathbf{5 0 \%})\end{array}$ & $\begin{array}{c}\text { Language organize } \\
(\mathbf{2 5 \%})\end{array}$ & $\begin{array}{c}\text { View contribution } \\
(\mathbf{2 5 \%})\end{array}$ \\
\hline & & & \\
\hline
\end{tabular}

For non-English majors with mixed English proficiency, if assessments were based on the results of students output, they would inevitably lose confidence if students were relatively weak. TSCA requires all students to participate and demands a variety of forms ,furthermore assessing content should be diversified so as to promote the depth and breadth of students' thinking, it is not only essential to focus on the form of language, but more importantly, encourage students' critical thinking.

b) Outside group evaluation: be scored by other groups.In the first period students were asked to prepare their own scoreboards A, B, and C, and an opinion book to take note of mistakes of other groups. The scoring standard is as follows:

TABLE II. OUT OF GROUP STANDARD

\begin{tabular}{|c|c|c|c|c|c|}
\hline $\begin{array}{c}\text { Group } \\
\text { order }\end{array}$ & $\begin{array}{c}\text { Language } \\
\text { accuracy and } \\
\text { scope }(\mathbf{4 0 \% )}\end{array}$ & $\begin{array}{c}\text { Discourse length } \\
\text { and continuity } \\
(\mathbf{2 0} \%)\end{array}$ & $\begin{array}{c}\text { Language } \\
\text { flexibility and } \\
\text { relevance (20\%) }\end{array}$ & $\begin{array}{c}\text { Knowledge } \\
(\mathbf{2 0 \%})\end{array}$ & grade \\
\hline & & & & & \\
\hline
\end{tabular}

Meanwhile, students made suggestion for other groups accordingly.

c) Evaluation of teacher: Teacher's evaluations are important in the practising of POA theory . Teachers must carefully organize classes and make efficient use of time In class. The classroom should not be made as a lively and active market where Learning does not actually happen. If teachers do not check in-group and outside group evaluation, reviews and summaries would never be treated seriously.Students will only be perfunctory. And one point must be made clear is that selective evaluation is more effective than comprehensive evaluation (Qiufang Wen . 2016).

Shuguang Sun (2017) pointed out that teachers should choose focuses in evaluation, and evaluate according to the principles of typicality, gradualism, and teaching ability. Based on these principles, assessments were made from four aspects: First, the progress of activities in each group was reviewed; Second, whether peers' comments were appropriate; Third, the flashing point of each task should be fingered out; Fourth, typical mistakes that most students made must be pointed out. The obvious drawbacks of students were the lack of sentence subject or predicate, Lack of convergence of language chapters, weak coherence and logic. in addition, their point of view about this topic was not deep enough. Many of these problems were not immediately resolved in the classroom. Therefore, after class, students need to supplement their assignments to deepen their consolidation of language knowledge, expand their thinking. Thus delayed assessments should be conducted.

\section{CONCLUSION}

Over the entire application process of POA theory, some questions should be pondered, and there are details worth paying attention to during each stage of out-put task driving, inputting-enabling, and assessing. 
A. In the Practice of POA Theory, the Driving Task Should Be Personalized and Set up in Layers, Emphasizing Students' Efforts of Trying Tasks Instead of Teachers' Role of Demonstration

The POA theory can be seen as a trial and error process to some extent. Trial error at the original level (output drive) - rectify through language input (input internalization) - Try again after learning (output) --error correction--- - Integrated output (delayed operation). The theory of behavioral learning of Thorndike - trial and error learning, can be seen as the foundation of psychology of POA teaching. In other words, the introduction of output is actually a process of trial and error for students. In POA theory, output task driven is not only the driving force of students, but also a process of trial and error. It is not only desire but also courage that makes students dare to speak. Encouraging students to try to complete the driving task (trial failure) is more important than the fine-grained output task design. Obviously, showing output tasks does not necessarily stimulate students' desire to learn. By allowing students to deeply participate in the task, their status will be better and they will be more focused and brave to make mistakes. The more obvious the mistakes are, the more the student can deeply understand his own deficiencies.

\section{B. To Take into Account of the Authenticity and Comprehensiveness of Evaluation}

In the practice of the POA theory, in-group and outgroup evaluations should be included in the final assessment. Without such mechanism, scoring is only a form, and the enthusiasm of student is not high. However, in out-group evaluation, students cannot assess each member of his group but only his representative. In order to pursue high scores within the group, students with good English skills were often assigned to present tasks on behalf of the group. Although teacher demanded that each student be given chances to perform tasks, fewer opportunities were given to students with weak foundations. How to promote the development of every student through evaluation? This is a question to be dealt with in practice.

\section{To Achieve Classroom Fairness and Make Classroom a Stage for Everyone Instead of a Personal English Show of a Few Excellent Students}

Those who boldly stood up and tried to express themselves were relatively well-founded students. Students with weak English skills only participate in activities within group. Therefore, to encourage all students, especially student with weak foundations, to boldly challenge difficult tasks is an issue that should be paid attention to in the evaluation system.

\section{To Motivate Students to Select Topics, Collect Information, and Make up for the Lack of POA Teaching Materials}

The process of collecting is also a process of selective learning. Knowledge of textbooks has been difficult to meet the needs of students. It is feasible for students to participate in the construction of teaching supplementary materials under the background of Internet+. Students take the initiative to choose what they want to learn, what they are interested, this is a good way of contributing to the POA practice.

Of course, we look forward to the specialized POA textbooks, and we also hope that related teaching resources will be shared. Teaching is an art that will never be perfect. The POA teaching approach expects more exchanges from peers.

\section{REFERENCES}

[1] Qiufang Wen:construction of production-oriented approach theoretical system .ForeignLanguage Teaching and Research.2015(4):547-558.

[2] Qiufang Wen:Output-driven Hypothesis in College English Teaching: reflections and Suggestions.Foreign Language World..2013.06.P14

[3] Qiufang Wen: "Teacher-Student Collaborative Assessment" A New Evaluation Form Created by the "Production-oriented Approach" [J]. Foreign Language world, 2016(5):37-43.

[4] Qiufang Wen:Chinese characteristics of "production-oriented approach"Modern foreign languages.2017(3):348-358.

[5] Lingli Zhang :Research on Teaching Effectiveness of "Productiontoriented Approach"Modern foreign languages.[J]2017.03.p369-376.

[6] Wenjuan Zhang:College English Classroom Teaching Experiment Based on "production-oriented Approach".Foreign Language Teaching and Research.P106-114

[7] Qiufang Wen:Output Drive-Input Enabling Hypothesis: An Attemp to Construct a Foreign Language Classroom Teaching Theory in Universities.Foreign Language Education in China.2014.02:p3-12

[8] Wenjuan Zhang:An Experimental Study of the Influence of "production-oriented Approach" on College English Writing.Modern foreign languages..[J]2017.03P377-385

[9] Shuguang Sun:Research on Reflective Practice of Teacher-Students Collaborative Assessment.Modern foreign languages.[J].2017.05 p397-407 